\title{
Differential Expression of Two Distinct Functional Isoforms of Melanopsin (Opn4) in the Mammalian Retina
}

\author{
Susana S. Pires, ${ }^{1 *}$ Steven Hughes, ${ }^{1 \star}$ Michael Turton, ${ }^{1}$ Zare Melyan, ${ }^{1}$ Stuart N. Peirson, ${ }^{1}$ Lei Zheng, ${ }^{1}$ Maria Kosmaoglou, ${ }^{2}$ \\ James Bellingham, ${ }^{3}$ Michael E. Cheetham, ${ }^{2}$ Robert J. Lucas, ${ }^{4}$ Russell G. Foster, ${ }^{1}$ Mark W. Hankins, ${ }^{1}$ and Stephanie Halford ${ }^{1}$ \\ ${ }^{1}$ Nuffield Laboratory of Ophthalmology, University of Oxford, Oxford OX3 9DU, United Kingdom, ${ }^{2}$ Molecular and Cellular Neuroscience, University College \\ London, Institute of Ophthalmology, London EC1V 9EL, United Kingdom, and ${ }^{3}$ Genetic Medicine, The University of Manchester, Manchester Academic \\ Health Science Centre, and ${ }^{4}$ Faculty of Life Sciences, University of Manchester, Manchester M13 9PT, United Kingdom
}

\begin{abstract}
Melanopsin is the photopigment that confers photosensitivity to a subset of retinal ganglion cells ( $\mathrm{pRGCs}$ ) that regulate many non-imageforming tasks such as the detection of light for circadian entrainment. Recent studies have begun to subdivide the pRGCs on the basis of morphology and function, but the origin of these differences is not yet fully understood. Here we report the identification of two isoforms of melanopsin from the mouse $0 p n 4$ locus, a previously described long isoform $(O p n 4 L)$ and a novel short isoform $(O p n 4 S)$ that more closely resembles the sequence and structure of rat and human melanopsins. Both isoforms, Opn4L and Opn4S, are expressed in the ganglion cell layer of the retina, traffic to the plasma membrane and form a functional photopigment in vitro. Quantitative PCR revealed that $O p n 4 S$ is 40 times more abundant than $O p n 4 L$. The two variants encode predicted proteins of 521 and 466 aa and only differ in the length of their C-terminal tails. Antibodies raised to isoform-specific epitopes identified two discrete populations of melanopsinexpressing RGCs, those that coexpress $0 \mathrm{pn} 4 \mathrm{~L}$ and $\mathrm{Opn} 4 \mathrm{~S}$ and those that express $0 \mathrm{pn} 4 \mathrm{~L}$ only. Recent evidence suggests that pRGCs show a range of anatomical subtypes, which may reflect the functional diversity reported for mouse Opn4-mediated light responses. The distinct isoforms of Opn4 described in this study provide a potential molecular basis for generating this diversity, and it seems likely that their differential expression plays a role in generating the variety of pRGC light responses found in the mammalian retina.
\end{abstract}

\section{Introduction}

The melanopsin gene (Opn4) encodes a functional photopigment involved in the mediation of nonvisual photoreceptive tasks, such as circadian entrainment, pupillary constriction, and masking of locomotor activity (for review, see Hankins et al., 2008). Melanopsin was originally isolated in 1998 from the melanophores of Xenopus, specialized light-sensitive cells in the skin (Provencio et al., 1998). Subsequently, Provencio et al. (2000) isolated melanopsin from mammals and demonstrated that it is expressed in a subset of ganglion cells in the inner retina (RGCs). Several studies, using a variety of approaches, went on to demonstrate that these RGCs ( $1-3 \%$ of the total), are intrinsically photosensitive (pRGCs) and project to several brain areas including the suprachiasmatic nuclei (SCN), the master circadian pace-

Received April 26, 2009; revised Aug. 13, 2009; accepted Aug. 16, 2009.

This work was supported by a Wellcome Trust Programme Grant (GR069714MA) to R.G.F., by a Biotechnology and Biological Sciences Research Council Grant to M.W.H. (BB/E021671/1), and by a D.Phil. GABBA Studentship to S.S.P. from Fundacão para a Ciência e Tecnologia, Portugal. Steven Hughes is funded by F. Hoffmann-La Roche. M.K. was funded by Fight for Sight. J.B. is grateful to the National Institute for Health Research Manchester Biomedical Research Centre and Manchester Academic Health Science Centre. We are grateful to Rosalie Crouch for providing the 11-cis-retinal, King-Wai Yau and Samer Hattar for the Opn4 mice, Neeraj Agarwal (Fort Worth) for providing the RGC -5 cells, and Francesca Cordeiro and Li Guo for advice on culture conditions. We also thank Sumathi Sekaran for useful discussions.

*S. S. Pires and S. Hughes contributed equally to this work.

Correspondence should be addressed to Russell G. Foster, Mark W. Hankins, or Stephanie Halford, Nuffield Laboratory of Ophthalmology, University of Oxford, Headley Way, 0xford OX6 9DU, UK, E-mail: russell.foster@ eye.ox.ac.uk, mark.hankins@eye.ox.ac.uk, or stephanie.halford@eye.ox.ac.uk.

DOl:10.1523/JNEUROSCI.2036-09.2009

Copyright $\odot 2009$ Society for Neuroscience 0270-6474/09/2912332-11\$15.00/0 maker, and the olivary pretectal nuclei (OPN) (Berson et al., 2002; Panda et al., 2002, 2005; Ruby et al., 2002; Lucas et al., 2003; Sekaran et al., 2003; Melyan et al., 2005; Qiu et al., 2005; Hattar et al., 2006).

An initial physiological study of the responses of pRGCs in mice revealed a diversity of melanopsin-dependent light responses described as transient, sustained and repetitive (Sekaran et al., 2003). Further work, using multielectrode array recording in the neonatal mouse retina, also demonstrated differences in functional responses based on sensitivity and latency (Tu et al., 2005). In addition it has been reported that in the primate retina there are two morphologically distinct subtypes of melanopsin RGCs, with dendrites that ramify in either the inner or outer strata of the inner plexiform layer (IPL) (Dacey et al., 2005). Similarly in the mouse retina, two types of melanopsin ganglion cells, termed M1 and M2, have been described (Hattar et al., 2006). Two further studies have extended this anatomical diversity to define three types of melanopsin-expressing cells. These are M1 which have dendrites in the outer IPL, close to the inner nuclear layer (INL), M2 which have dendrites in the inner IPL, close to the ganglion cell layer (GCL), and cells that are bistratified, with dendrites in the same strata as both M1 and M2 cells (Viney et al., 2007; Schmidt et al., 2008). Recently it has been suggested that these subtypes of melanopsin-expressing cells might differentially innervate retino-recipient brain areas (Hattar et al., 2006; Baver et al., 2008).

The isolation and subsequent characterization of melanopsin revealed that the $\mathrm{C}$-terminal tails of the deduced amino acid se- 
quences from human and mouse differed significantly (Provencio et al., 2000). This observation as well as the finding that rat Opn4 is more similar to the human sequence than to mouse led us to undertake a more detailed analysis of the melanopsin gene structure. Here we report the existence of two isoforms of Opn4 (Opn4L and Opn4S), in the adult retina, generated by alternate splicing of a single melanopsin gene in the mouse genome. We go on to demonstrate that both isoforms encode functional photopigments and are differentially expressed in subpopulations of RGCs, a finding that offers an insight into their role in the mammalian retina.

\section{Materials and Methods}

Animals. Wild-type mice (C3H/He; not carrying $r d$ mutation) and $\mathrm{Opn}^{-/-}\left(\right.$tau-LacZ $\left.{ }^{+/+}\right)$mice (mixed C57BL/6 and 129/SvJ background) (Hattar et al., 2002) were housed under a 12:12 LD cycle with food and water ad libitum. Animals were killed at ZT 6-10, according to Schedule 1 of the UK Home Office Animals (Scientific Procedures) Act 1986. Eyes were removed and either processed for immunocytochemistry or retina dissected and snap frozen on dry ice at $-80^{\circ} \mathrm{C}$ until required.

RNA extraction and cDNA synthesis. Retinal tissue was homogenized in $1 \mathrm{ml}$ of TRIzol (Invitrogen) using a micropestle. Total RNA was then extracted according to the manufacturer's instructions, resuspended in TE, and stored at $-80^{\circ} \mathrm{C}$ before use. A $0.5 \mathrm{mg}$ quantity of total RNA was DNase treated (Sigma-Aldrich) and reverse transcribed with an oligo $\mathrm{d}(\mathrm{T})_{\mathrm{n}}$ primer using the RetroScript kit (Ambion) according to the manufacturer's instructions.

Isolation of two isoforms of mouse Opn4. Primers were designed in exon 8 (mOpn4 8F 5'-GCTACCGCTCTACCCACC-3') and around the predicted stop codons of the putative long and short isoforms (mOpn4 long 5'-CTACAGATGTCTGAGAGTCAC-3', mOpn4 short 5'-CTACATCCCGAGATCCAGACT-3'). PCR was then performed under the following conditions: an initial denaturation step at $94^{\circ} \mathrm{C}$ for $3 \mathrm{~min}$, then $94^{\circ} \mathrm{C}$ for $30 \mathrm{~s}, 56^{\circ} \mathrm{C}$ for $30 \mathrm{~s}$, and $72^{\circ} \mathrm{C}$ for $30 \mathrm{~s}$ for 35 cycles, followed by a final extension at $72^{\circ} \mathrm{C}$ for $7 \mathrm{~min}$. Each $25 \mu \mathrm{l}$ reaction contained $0.2 \mathrm{~mm}$ dNTPs, $0.2 \mu \mathrm{M}$ each primer, $1 \mu \mathrm{l}$ of template cDNA, prepared as described above, and $1 \mathrm{U}$ of Taq polymerase (Thermoprime plus, ABgene). Using primer pairs mOpn4 8F/mOpn4 long and mOpn4 8F/mOpn4 short generated products of $425 \mathrm{bp}$ and $260 \mathrm{bp}$ respectively. These fragments were cloned into pGEM-T Easy (Promega) according to the manufacturer's instructions and sequenced. Full-length coding sequences of both isoforms were generated using PCR with a primer to the start site of mOpn4 (mOpn4 1F 5'-ATGGACTCTCCTTCAGGA-3') and mOpn4 long or mOpn 4 short. PCR was performed using Platinum Taq Supermix (Invitrogen) with an initial denaturation step at $94^{\circ} \mathrm{C}$ for $3 \mathrm{~min}$, then $94^{\circ} \mathrm{C}$ for $30 \mathrm{~s}, 54^{\circ} \mathrm{C}$ for $30 \mathrm{~s}$, and $72^{\circ} \mathrm{C}$ for $1 \mathrm{~min} 30 \mathrm{~s}$ for 35 cycles, followed by a final extension at $72^{\circ} \mathrm{C}$ for $7 \mathrm{~min}$. The products of $1566 \mathrm{bp}$ and 1401 bp were cloned into pGEM-T Easy and sequence verified.

3' RACE. 3' RACE ready cDNA was synthesized with the RLM-RACE kit (Ambion) using $1 \mu \mathrm{g}$ of retinal RNA and the $3^{\prime}$ adapter primer. First round RACE was performed with primer mOpn4 6F (5'-GGAAGATGGCCAAGGTCGCA-3') and the $3^{\prime}$ RACE outer primer (5'-GCGAGCACAGAATTAATACGACT- $3^{\prime}$ ) according to the manufacturer's protocol, but briefly, PCR was performed under the following conditions: an initial denaturation step at $94^{\circ} \mathrm{C}$ for $3 \mathrm{~min}$, then $94^{\circ} \mathrm{C}$ for $30 \mathrm{~s}$, $60^{\circ} \mathrm{C}$ for $30 \mathrm{~s}$, and $72^{\circ} \mathrm{C}$ for $30 \mathrm{~s}$ for $35 \mathrm{cycles}$, followed by a final extension at $72^{\circ} \mathrm{C}$ for $7 \mathrm{~min}$. One microliter of first-round product was used in a nested PCR with the primers mOpn $48 \mathrm{~F}$ and $3^{\prime}$ RACE inner primer (5'-CGCGGATCCGAATTAATACGACTCACTATAGG-3') using the same conditions. The two products obtained were cloned into PGEM-T easy and sequenced.

Quantitative PCR. Quantitative real-time PCR (qPCR), using cDNA synthesized as described above and the primer pairs mOpn 4 8F/mOpn 4 long, mOpn 4 8F/mOpn4 short, was performed using Sybr Green I or TaqMan mastermixes on a StepOne thermal cycler (Applied Biosystems). Relative quantification of transcript levels was performed as previously described (Peirson et al., 2003). Two genes were used for normalization, acidic ribosomal phosphoprotein $(A R P)$ and $\beta$-actin, primer sequences were as previously described (Peirson et al., 2004).

Cell culture. RGC-5 cells were grown in DMEM/F12 with Glutamax-I (Invitrogen) and 10\% FBS and 1\% (v/v) penicillin/streptomycin (Sigma). Neuro-2A cells (ECACC) were cultured in DMEM (Sigma) supplemented with $10 \%$ FBS, 2 mM L-glutamine, and $1 \%$ (v/v) penicillin/ streptomycin. All cells were incubated in a humidified chamber at $37^{\circ} \mathrm{C}$ with $5 \% \mathrm{CO}_{2}$, fed fresh media every $2-3 \mathrm{~d}$, and passaged before reaching confluence.

Transfection. The full-length coding regions of both isoforms of Opn4 were cloned into the expression vector pIRES2-AcGFP (BD Biosciences). Constructs were sequence verified and DNA for transfections was prepared using a plasmid Midiprep kit (Qiagen). Transfection of RGC-5 cells was performed using the Lipofectamine Plus transfection reagent (Invitrogen) according to the manufacturer's guidelines and as previously described (Kosmaoglou and Cheetham, 2008). Transfection of Neuro-2A cells was performed using the Genejuice transfection reagent (Novagen) according to the manufacturer's guidelines. Briefly, Neuro-2A cells were seeded at a density of $2 \times 10^{5}$ cells per $35 \mathrm{~mm}$ Petri dish. Twenty-four hours after seeding, cells were incubated in RPMI media (Sigma) containing $2 \mu \mathrm{g}$ of plasmid DNA and $6 \mu \mathrm{l}$ of Genejuice reagent for $6 \mathrm{~h}$. Cells were then fed normal cell culture media and cultured for $48 \mathrm{~h}$ before protein isolation and ICC.

Whole-cell electrophysiology. After transfection ( $24 \mathrm{~h})$, cells were differentiated by the addition of $20 \mu \mathrm{M}$ retinoic acid to the culture media for a further $48 \mathrm{~h}$ in the dark. All subsequent steps were performed under dim red light. Before patch-clamp recordings, cells were perfused with extracellular saline (140 mM NaCl, $4 \mathrm{~mm} \mathrm{KCl}, 1 \mathrm{~mm} \mathrm{MgCl}, 2 \mathrm{~mm} \mathrm{CaCl}_{2}, 5 \mathrm{~mm}$ glucose, and $10 \mathrm{~mm}$ HEPES, $\mathrm{pH}$ adjusted to 7.4 with $\mathrm{NaOH}$ ) containing $20 \mu \mathrm{M}$ 9-cis-retinal (Sigma) or 11-cis-retinal (kind gift from Rosalie Crouch, Medical University of South Carolina, Charleston, SC) for $2 \mathrm{~h}$ in the dark. Glass microelectrodes were made from $1.5 \mathrm{~mm}$ diameter thin walled glass capillaries (Harvard Apparatus), with a final open pipette resistance of 3-5 M $\Omega$. Internal pipette saline contained $140 \mathrm{~mm} \mathrm{KCl,} 10$ mM NaCl, 1 mм $\mathrm{MgCl}_{2}, 10$ mм HEPES, and $10 \mathrm{~mm}$ EGTA, with osmolarity adjusted to $285 \pm 5 \mathrm{mOsmol} / \mathrm{L}$ and $\mathrm{pH}$ to 7.4 with $\mathrm{KOH}$. Successfully transfected cells were identified based on expression of GFP and then dark adapted for at least $1 \mathrm{~h}$ before recordings, subsequent visualization of cells was performed using infrared light. Whole-cell recordings were performed at room temperature $\left(22-25^{\circ} \mathrm{C}\right)$ using an Axopatch 200B amplifier and PClamp9 data acquisition software (Molecular Devices) with a sampling rate of $20 \mathrm{kHz}$. Whole-cell currents were recorded from cells voltage clamped at holding potentials of $-50 \mathrm{mV}$. Access resistance during recordings was $<20 \mathrm{M} \Omega$. Light stimuli were generated using a Cairn Optoscan Xenon arc source comprising a slit monochromator. Stimuli were $10 \mathrm{~s}$ in duration with a $20 \mathrm{~nm}$ half-bandwidth. Irradiance was measured using an optical power meter (Macam Photometrics) and converted to photon flux. The intensity of light used was $8 \times 10^{14}$ photons $\cdot \mathrm{cm}^{-2} \cdot \mathrm{s}^{-1}$ and is $\sim 1 \log$ unit above threshold. The magnitude of responses was defined by the peak sustained current measured using Clampfit analysis software (Molecular Devices).

Antibodies. Specific polyclonal antibodies were raised to each Opn4 isoform using different animal models (OPN4L: rabbit; OPN4S: goat) to enable colocalization. An additional rabbit polyclonal antibody was raised to the $\mathrm{N}$ terminus of melanopsin, which is common to both isoforms (PAS8331). Each polyclonal antibody was raised against a 15 aa synthetic peptide conjugated to KLH by Harlan UK, according to their standard procedures (short: SPQTKGHLPSLDLGM; long: PHPHTSQFPLAFLED, N-term: MDSPSGPRVLSSLTQ, shown on Fig. $1 A$ ). All antibodies were affinity purified before use (Thiolink gel kit, Severn Biotech). A chicken anti- $\beta$-galactosidase antibody (ab9361, Abcam) was used for localization of $\beta$-gal expression in tau-lac $Z^{+/-}$mice. SDS-PAGE gel loading was assessed using a rabbit polyclonal anti- $\beta$ actin antibody (ab8227, Abcam). Secondary antibodies: for Western blotting, donkey anti-goat and anti-rabbit IgG HRP-linked secondary antibodies were used (SC2304 and SC2305, Insight Biotechnology). For secondary labeling in immunofluorescence studies, Cy3-labeled donkey anti-rabbit antibody (Jackson Immunoresearch), Alexa 555-labeled goat anti-rabbit, Alexa 568 donkey anti-goat, Alexa 488 and 555 donkey anti- 


\begin{abstract}
A
Human MNPPSGPRVPSPTQEPSCMATPA-PPSWWDSSQSSISSLGRLPSISPTAPGTWAAAWVPLPTVDVPDHAHYTLGTVILLVGLTGMLGNL Rat MNSPSESRVPSLTQDPSFTASPALLQGIWNSTQN-ISVRVQLLSVSPTT PGLQAAAWVPFPTVDVPDHAHYTLGTVILLVGLTGMLGNL Mouse MDSPSGPRVLSSLTQDPSFTTSPA-LQGIWNGTQN-VSVRAQLLSVSPTTSAHQAAAWVPFPTVDVPDHAHYTLGTVILLVGLTGMLGNL 23 II 3 III Human TVIYTFCRSRSLRTPANMFI INLAVSDFLMSFTQAPVFFTSSLYKQWLFGETGCEFYAFCGALFGISSMITLTAIATIRYLVITRPLATF TVIYTFCRNRGLRTPANMLI INLAVSDFLMSFTOAPVFFASSLYKKWLFGETGCKFYAFCGAVFGIVSMITLTAIAMDRYLVITRPLATI Mouse TVIYTFCRNRGLRTPANMFI INLAVSDFLMSVTQAPVFFASSLYKKWLFGETGCE YYFCGAVFGITSMITLTAIAMDRYLVITRPLATI GVASKRRAAFVLLGVWLYALAWSLPPFFGWSAYVPEGLLTSCSWDYMSFTPAVRAYTMLLCCFVFFLPLLIIIYCYIFIFRAIRETGRAL

Rat

Mouse 作 GRGSKRRTALVLLGVWLYALAWSLPPFFGWSAYVPEGLLTSCSWDYMTFTPQVRAYTMLLFCFVFFLPLLI I IFCY IFIFRA IRETGRAC QTFGACKGNGESLWQRQRLQSECKMAKIMLLVILLFVLSWAPYSAVALVAFA A ${ }^{7}$ YHVLTPYMSSVPAVIA EGCGESPLR-RRQWQR--LQSEWKMAKVALIVILLFVLSWAPYSTVALVGFAGYSHILTPYMSSVPAVIA IASA I HNP I IYA ITHPKYRA EGCGESPLRQRRQWQR--LQSEWKMAKVALIVILLFVLSWAPYSTVALVAFAGYSHILTPYMSSVPAVIA KASAIHNPI IYAITHPKYRV

8,9

Human AIAQHLPCLGVLLGVSRRHSRPYPSYRSTHRSTLTSHTSNLSWISIRRRQESLGSESEVGWTHMEAAAVWGAAQQANGRSLYGQGLEDLE AIAQHLPCLGVLLGVSGQRSHPSLSYRSTHRSTLSSQSSDLSWISGQKRQESLGSESEVGWTDTETTAAWGAAQQASGQSFCSHDLEDGE 446 Mouse AIAQHLPCLGVLLGVSGQRSHPSLSYRSTHRSTLSSQSSDLSWISGRKRQESLGSESEVGWTDTETTAAWGAAQQASGQSFCSQNLEDGE

9,10

Rat VKAPSSPQEOKSKTP-KTKRHIPSQDPRM

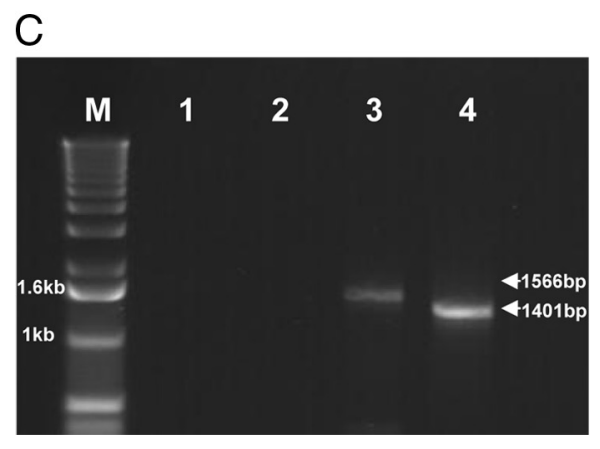

Figure 1. A, Alignment of mouse, rat and human 0pn4 deduced amino acid sequences. Residues that are identical in two out the three sequences are shaded. The seven probable transmembrane domains are marked by red lines above the sequence and numbered using roman numerals. The characteristic features of an opsin are shown boxed: lysine (K) to form a Schiff's base at position 337 ; tyrosine $(\mathrm{Y})$, a possible counterion at position 145; aspartate, arginine, and tyrosine (DRY) tripeptide for transducin binding at position $166-168$; and cysteines (C) at positions 142 and 220 for disulfide bridge formation (numbers correspond to the mouse sequence). The intron-exon boundaries are delineated by vertical blue lines and are numbered. The epitopes of the $\mathrm{N}$-terminal antibody (PAS8331) and OPN4L are shown boxed. Accession numbers are as follows: Homo sapiens NM_033282, Rattus norvegicus NM_138860, Mus musculus NM_013887. B, Alignment of amino acids encoded by rat Opn4 exons 9 and 10 with those of the newly identified mouse Opn4S showing that the mouse isoform exon 9 is 8 aa shorter than the rat sequence. Boxes show the epitopes of 0pn4S and the (-terminal rat antibody (for more details, see Discussion). C, Amplification of Opn4L and Opn4S coding regions from adult retina cDNA. Products are 1566 bp and 1401 bp. M, Marker (1 kb ladder, Invitrogen); lane 1, no template control for Opn4L primers; lane 2, no template control for Opn4S primers; lane 3, Opn4L; lane 4, Opn4S.

rabbit, and Alexa 488 goat anti-chicken antibodies (Invitrogen) were used as stated.

Western blotting. Retinal tissue samples were homogenized in $2 \%$ $(\mathrm{w} / \mathrm{v})$ SDS, $10 \mathrm{~mm}$ DTT in PBS with mini complete protease inhibitors (Roche) and centrifuged at 23,000 $\times g$ for $30 \mathrm{~min}$. Transiently transfected cells were centrifuged at $1000 \times g$ and the resulting cell pellets were washed with PBS and resuspended in $200 \mu$ l of lysis buffer (1\% (w/v) DM (Sigma), 5 mm EDTA in PBS with mini complete protease inhibitors) before passage through a 25 ga needle $\times 10$. The lysate was incubated at $4^{\circ} \mathrm{C}$ for $15 \mathrm{~min}$ and then centrifuged at $23,000 \times g$ at $4^{\circ} \mathrm{C}$ for $30 \mathrm{~min}$. The resulting supernatant fraction of both sample preparations was combined 1:1 with modified sample buffer without heat treatment (Saliba et al., 2002). Samples were resolved on an 8\% SDS-PAGE minigel and electrotransferred onto PVDF membrane (Bio-Rad). The membrane was blocked in 5\% (w/v) BSA in Tris-buffered saline, 1\% (v/v) Tween 20 (TBST) for $1 \mathrm{~h}$ and incubated overnight at $4^{\circ} \mathrm{C}$ with primary antibody (diluted in $5 \%(\mathrm{w} / \mathrm{v})$ BSA in TBST). Blots were washed in TBST and incubated with HRP linked secondary antibody (Autogen Bioclear) for $1 \mathrm{~h}$. Following incubation, the blots were washed in TBST and developed using an ECL system (Thermo Scientific). Immunoreactivity was detected by exposure of the blots to $\mathrm{x}$-ray film and subsequent development (XOgraph Imaging Systems). To assess gel loading, membranes were stripped following ECL development, by incubation at $55^{\circ} \mathrm{C}$ in $87.7 \mathrm{~mm}$ Tris, $\mathrm{pH} 6.8,2 \%(\mathrm{w} / \mathrm{v})$ SDS, and $0.1 \mathrm{~m}$ DTT for $30 \mathrm{~min}$. Stripped blots were washed and blocked as before, before incubation with $\beta$-actin antibody.

Immunocytochemistry. Fluorescent immunolabeling was performed using standard techniques. Briefly, all slides were blocked for $1 \mathrm{~h}$ at room 
Table 1. Comparison of exon sizes of human, rat, and mouse melanopsin

\begin{tabular}{cccc}
\hline & \multicolumn{2}{l}{ Size (bp) } & Rat \\
\cline { 2 - 4 } Exon & Human & 144 & Mouse \\
\hline $1^{a}$ & 144 & 146 & 141 \\
2 & 146 & 134 & 146 \\
3 & 134 & 204 & 134 \\
4 & 204 & 172 & 204 \\
5 & 172 & 156 & 172 \\
6 & 165 & 108 & 159 \\
7 & 108 & 181 & 108 \\
8 & 181 & 141 & 181 \\
9 & 144 & 39 & 321 \\
10 & 39 & &
\end{tabular}

aength from start codon.

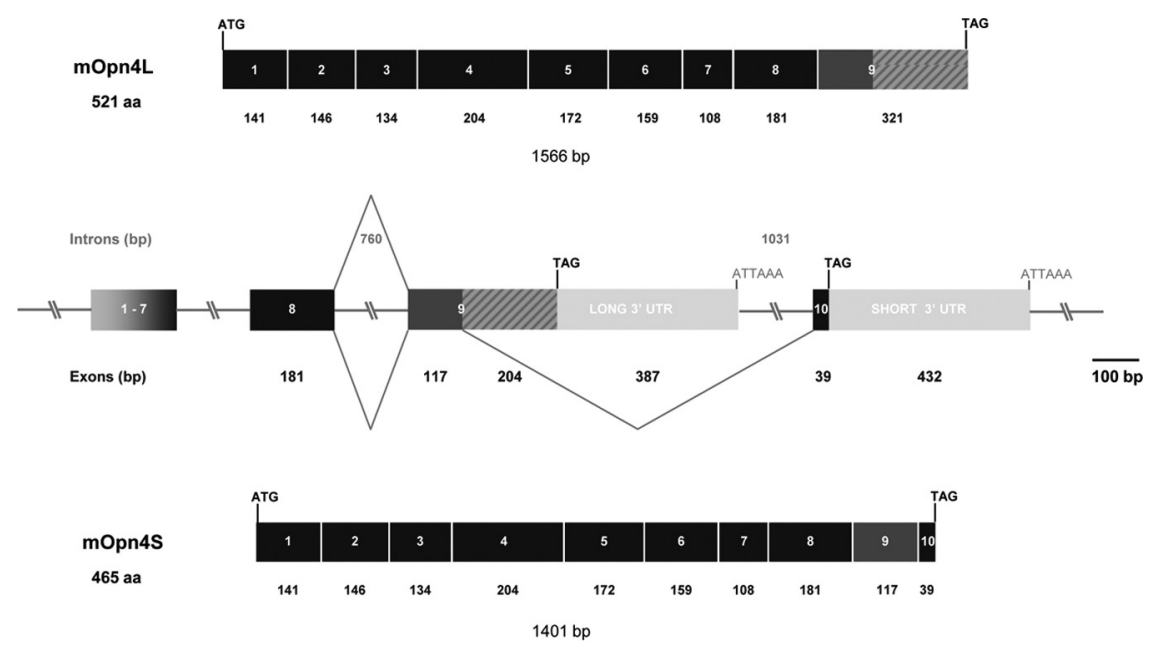

Figure 2. Schematic diagram of the genomic structure of mouse Opn4. The mouse Opn4 gene consists of 10 exons that span $\sim 9.6 \mathrm{~kb}$ of genomic DNA. Exons are shown as boxes and introns as lines; all are to scale except for exons 1-7 and regions of intronic DNA larger than $1 \mathrm{~kb}$ that are represented as slashed lines. Intron and exon sizes are marked. The start and stop codons in each gene are also indicated, as are the polyadenylation signals. The gene gives rise to two splice variants, the m0pn $4 \mathrm{~L}$ isoform generated by retention of intron 9 and $m 0 p n 4 S$ by splicing to exon 10. The products generated by these two events are shown.

temperature (RT) in PBS with 10\% serum from the same species as the corresponding secondary antibodies. All antibodies were diluted in PBS with $2.5 \%$ serum. All wash steps were performed with PBS Tween $(0.1 \%)$ for $5 \mathrm{~min} \times 4$. RGC- 5 cells were fixed with methanol at $-20^{\circ} \mathrm{C}$ for 20 min, incubated with PAS8331 antibody (1:500) for $1 \mathrm{~h}$ at RT, followed by a Cy3-labeled secondary (1:100) for $1 \mathrm{~h}$ at RT. Slides were counterstained with DAPI $(2 \mu \mathrm{g} / \mathrm{ml})$ in PBS for $15 \mathrm{~min}$ then mounted with fluorescent mounting medium (DAKO). Neuro-2A cells were fixed with 4\% PFA (Pierce) for $15 \mathrm{~min}$ and permeabilized with $0.05 \%$ Triton-X in PBS for 5 min at RT. PAS8331, anti-Opn4L and anti-Opn4S antibodies were incubated for $1 \mathrm{~h}$ at RT diluted 1:100. Alexa-labeled secondary antibodies were incubated for $1 \mathrm{~h}$ at RT diluted 1:400. Slides were mounted with anti-fade mountant with DAPI (Invitrogen). Removal, fixation, and cryostat sectioning of whole mouse eyes was performed as described previously (Sekaran et al., 2007). Whole eye sections (16 $\mu \mathrm{m}$ ) were permeabilized with $0.2 \%$ Triton-X in PBS for $20 \mathrm{~min}$ at RT. Primary antibodies [anti-Opn4L (1:100), anti-Opn4S (1:100), anti- $\beta$-gal (1:400)] were incubated for $18 \mathrm{~h}$ at $4^{\circ} \mathrm{C}$. Alexa-labeled secondary antibodies were incubated for $1 \mathrm{~h}$ at RT diluted 1:200. For double-labeling experiments, slides were incubated with primary antibodies and secondary antibodies in a sequential manner: Opn $4 \mathrm{~S}$ then Opn $4 \mathrm{~L}$ or $\beta$-gal. Slides were mounted with anti-fade mountant with DAPI (Invitrogen). Fluorescent images were collected using a Carl Zeiss LSM510 confocal laser-scanning microscope, excitation 405,488 , and $543 \mathrm{~nm}$ with emission wavelengths of $420-450,505-530$, and 550-754 nm for DAPI, green, and red fluorescence, respectively.

\section{Results}

Two isoforms of mouse Opn4 in the adult retina

The published mouse Opn4 sequence (AF147789) is 2137 bp and encodes a predicted protein of 521 aa containing all of the expected features of an opsin (Provencio et al., 2000). Alignment of the predicted amino acid sequences of human (NM_033282), mouse (NM_013887), and rat (NM_138860) melanopsins (Fig. 1A) shows that the mouse Opn4 sequence has a longer $\mathrm{C}$ terminus than either human or rat. The human sequence consists of 10 exons spanning $11.9 \mathrm{~kb}$ of genomic sequence on chromosome 10q23.2 (Provencio et al., 2000). Using TBLASTN searches of both the mouse and rat genomes, with the corresponding Opn4 amino acid sequence, enabled us to determine the genomic structure of these genes. The rat Opn 4 gene also consists of 10 exons spanning $9.2 \mathrm{~kb}$ on chromosome 16; however the mouse gene only has 9 exons spanning $7.8 \mathrm{~kb}$ of genomic sequence on chromosome 14 . This discrepancy led us to examine the genomic sequence of the mouse Opn 4 locus in more detail. The sizes of the exons of all three genes are shown in Table 1 . This comparison reveals that exon 9 in mouse is $321 \mathrm{bp}$, whereas exon 9 in human is $144 \mathrm{bp}$ and in rat $141 \mathrm{bp}$. A BLAST search using the nucleotide sequence of the rat melanopsin gene (NM_138860) against the mouse genome identified a region downstream of exon 9 showing $87 \%$ identity at the nucleotide level to rat exon 10. This was the first indication that there may be two isoforms of the mouse melanopsin gene generated by alternate splicing.

To determine whether this potential exon 10 is actually expressed in mouse and produces a transcript that gives rise to a short isoform similar to that seen in both human and rat, primers were designed to this novel sequence. PCR was performed using adult mouse retina cDNA as template using a forward primer in exon 8 (mOpn $48 \mathrm{~F}$ ) and reverse primers designed around the predicted stop codons of both isoforms (mOpn4 long and mOpn4 short). Both primer pairs generated products: $8 \mathrm{~F} /$ long, the expected fragment of $425 \mathrm{bp}$ but $8 \mathrm{~F} /$ short produced a band of $260 \mathrm{bp}$ compared with the predicted $284 \mathrm{bp}$. Sequence analysis showed the $8 \mathrm{~F} /$ long fragment has $100 \%$ identity to the expected sequence. However the $8 \mathrm{~F} /$ short fragment was indeed 24 bp shorter than the rat sequence. This discrepancy occurs because exon 9 in the mouse short isoform is 117 bp compared with the $141 \mathrm{bp}$ in rat, resulting in the predicted amino acid sequence being 8 aa shorter (Fig. $1 B$ ).

To verify this result and to confirm the presence of both isoforms in adult mouse retina, primers were designed to amplify the complete coding sequences. Using the primer pairs Opn4 1F/long and Opn4 1F/short generated products of $1566 \mathrm{bp}$ and 1401 bp respectively using wild-type retinal cDNA as template, cDNA from mice where Opn4 has been replaced with tau-lacZ $\left(\right.$ tau-lac $\left.Z^{+/+}\right)$(Hattar et al., 2003) was used as a negative control (Fig. 1C). These products were sequenced and comparison with the mouse genome database enabled the genomic structure to be confirmed. The first 1362 nt of each clone were identical, corre- 
sponding to exons $1-8$. A schematic diagram of the genomic structure of the gene is shown in Figure 2 which also demonstrates how the alternate splicing occurs to generate the two isoforms, Opn4L (GenBank accession number EU303118) and Opn4S (GenBank accession number EU303117).

The final verification of the presence of both isoforms in adult mouse retina was achieved using 3' RACE which generated two fragments of $857 \mathrm{bp}$ and $930 \mathrm{bp}$. Sequence analysis showed that the $857 \mathrm{bp}$ fragment, corresponding to the long isoform (Opn4L), consisted of 425 bp of coding sequence (104 bp of exon 8 and $321 \mathrm{bp}$ of exon 9) and 432 bp of 3' UTR contiguous to exon 9. This is shown schematically in Figure 2 and the sequence shown in Figure $3 A$. This fragment encodes the $\mathrm{C}$ terminus originally reported by Provencio et al. (2000). The second fragment of $930 \mathrm{bp}$, corresponding to the short isoform $(\mathrm{Opn} 4 \mathrm{~S})$ is composed of $260 \mathrm{bp}$ of coding sequence split across 3 exons (104 bp of exon $8,117 \mathrm{bp}$ of exon 9 , and $39 \mathrm{bp}$ of exon 10). The remaining $670 \mathrm{bp}$ of $3^{\prime}$ UTR is contiguous to the newly identified exon 10 shown in Figures 2 and 3B. Both clones contained polyadenylation signals (ATTAAA in the long $3^{\prime}$ UTR and AATAAA in the short 3' UTR) shown boxed in Figure $3, A$ and $B$. Together, these data confirm the presence of two isoforms, Opn $4 L$ (EU303118) and Opn4S (EU303117), in the adult mouse retina. We also have preliminary reverse transcription-PCR evidence for a long isoform of human melanopsin (OPN4) indicating that a similar splicing mechanism may be present in the human retina (S. S. Pires and S. Halford, unpublished data).

Quantitative PCR was then used to determine the relative abundance of each isoform. The specificity of the $O p n 4 L$ and $O p n 4 S$ primers was determined by melting curve analysis (supplemental Fig. $1 \mathrm{~A}$, available at www.jneurosci.org as supplemental material) as well as by amplification of a dilution series (standard curve) based on $O p n 4 L$ and $S$ cloned into the vector pIRES-AcGFP (supplemental Fig. $1 B$, available at www.jneurosci.org as supplemental material). Both isoforms exhibited comparable amplification efficiency and were detectable in the mouse retina although the Opn4S transcript was present at levels $\sim 40 \times$ more than Opn $4 L$ (supplemental Fig. 1C, available at www.jneurosci.org as supplemental material).

Opn4L and Opn4S encode predicted proteins of 521 and 466 aa respectively, with the first 454 aa being identical. Both contain all the characteristic features of an opsin and only differ in the lengths of their C-terminal tails (Fig. 1A,B). Prediction of

$\mathrm{B}$
A mOpn4 8F EXON 8 GCTACCGCTCTACCCACCGCTCCACATTGAGCAGCCAGTCCTCAGACCTCAGCTGGATCT

$\begin{array}{lllllllllllllllllllll}Y & R & S & T & H & R & S & T & L & S & S & Q & S & S & D & L & S & W & I & S & 401\end{array}$ CTGGACGGAAGCGTCAAGAGTCCCTGGGTTCTGAGAGTGAAGTGJGCTGGACAGACACAG 120 $\begin{array}{lllllllllllllllllllll}G & R & K & R & Q & E & S & L & G & S & E & S & E & V & G & W & T & D & T & E & 421\end{array}$ AAACAACCGCTGCATGGGGAGCTGCCCAGCAAGCAAGTGGACAGTCCTTCTGCAGTCAGA 180 $\begin{array}{lllllllllllllllllllll}\text { T } & \text { T } & \text { A } & \text { A } & \text { W } & G & \text { A } & \text { A } & Q & Q & \text { A } & \text { S } & \text { G } & \text { Q } & \text { S } & \text { F } & \text { C } & \text { S } & Q & \text { N } & 441\end{array}$ ACCTAGAAGATGGAGAACTCAAGGCCTCTTCCAGCCCCCAGGTACAGAGATCTAAGACTC 240 $\begin{array}{lllllllllllllllllllll}\text { L } & \text { E } & \text { D } & \text { G } & \text { E } & \text { L } & \text { K } & \text { A } & \text { S } & \text { S } & \text { S } & \text { P } & \text { Q } & \text { V } & Q & \text { R } & \text { S } & \text { K } & \text { T } & \text { P } & 461\end{array}$ CCAAGGTGCCTGGACCCAGTACCTGCCGCCCTATGAAAGGACAGGGAGCCAGGCCAAGTA 300 $\begin{array}{lllllllllllllllllllll}\text { K } & V & P & G & P & S & T & C & R & P & M & K & G & Q & G & A & R & P & S & S & 481\end{array}$ GCCTAAGGGGTGACCAGAAAGGCAGGCTTGCTGTGTGCACAGGCCTCTCAGAGTGTCCCC 360

$\begin{array}{lllllllllllllllllllll}\text { L } & \text { R } & G & \text { D } & Q & \text { K } & \text { G } & \text { R } & \text { L } & \text { A } & \text { V } & \text { C } & \text { T } & \text { G } & \text { L } & \text { S } & \text { E } & \text { C } & \text { P } & \text { H } & 501\end{array}$ ATCCCCATACATCCCAGTTTCCCCTTGCTCTCCTAGAGGATGATGTGACTCTCAGACATC 420

$\begin{array}{lllllllllllllllllllllll}\mathbf{P} & \mathrm{H} & \mathbf{T} & \mathrm{S} & \mathrm{Q} & \mathbf{F} & \mathrm{P} & \text { L } & \text { A } & \text { L } & \text { L } & \text { E } & \text { D } & \text { D } & \text { V } & \text { T } & \text { L } & \text { R } & \text { H } & \text { L } & 521\end{array}$

TGTAGcagggtctaagtatgatctgtatctaggggaatatctgcatgtgactgtgtagct 480

ctgcgcatgacatgctgtcagctatgttgtaccatatgtatatgtagagtatgcatataa 540 cttatgtgcccttgaagatatgtggcctacagcagagaacaactcatgcgtgtgtggacc 600 atgttcctggcatatatgctctctgtcactgtgatgcctctgtgttgtgtgggtgacaga 660 gtgtgatggtgttcacctctctgcgcgggttttgatgctgggcaaacacggggaagggag 720 ctgcaagccatgtactagctcactgccgatggcctgtgctcaagatgtcaccgaggagaa 780 cacttgtagct ATTAAAaaggccagctgtcagctccagtgcctatggaaaaaaaaa 840 aaaaaaaaaaaaaaaa GCTACCGCTCTACCCACCGCTCCACATTGAGCAGCCAGTCCTCAGACCTCAGCTGGATCT

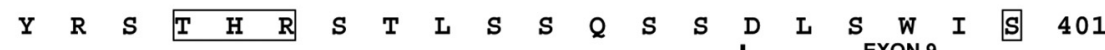
CTGGACGGAAGCGTCAAGAGTCCCTGGGTTCTGAGAGTGAAGTGJGCTGGACAGACACAG 120 $\begin{array}{lllllllllllllllllllll}G & R & K & R & Q & E & S & L & G & S & E & S & E & V & G & W & T & D & T & E & 421\end{array}$ AAACAACCGCTGCATGGGGAGCTGCCCAGCAAGCAAGTGGACAGTCCTTCTGCAGTCAGA 180

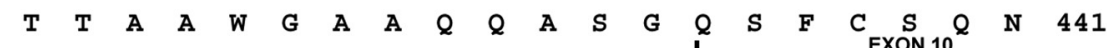
ACCTAGAAGATGGAGAACTCAAGGCCTCTTCCAGCCCCCAGACCAAGGGACACCTCCCCA 240 $\begin{array}{lllllllllllllllllllll}\text { L } & \text { E } & \text { D } & \text { G } & \text { E } & \text { L } & K & \text { A } & \text { S } & \text { S } & \text { S } & \text { P } & Q & \text { T } & \text { K } & \text { G } & \text { H } & \text { L } & P & S & 461\end{array}$ GTCTGGATCTCGGGATGTAGgatgcccactggecctcctttcttctggtacttgcccag 300

$\begin{array}{lllllll}\text { L } & D & \text { L } & \text { G } & \text { M } & * & 466\end{array}$

ccccgtcacctccccatcccatgcacagacccaggattatgtcacaagcctggaagcttt 360 gaaggtgttcctgtcactcgtgccacactggatacgaatctccggcccctttccacgccg 420 cgaagcacagtctgccgctactcagctcagcagccacactgggccccgcctgaagcacga 480

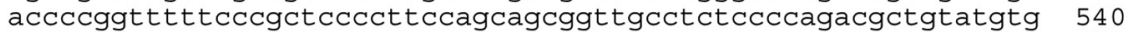
ctgcgattgtccagacaatgacaatggcgatggcactggggaacacatcatttatttatg 600 agataacatcttggccagctttcacaaccaggccggacatctcattggttcagaaagcc 660 cttccccgcgtccagggctcaaaagctgaacacagactttactttgtgcactgggaatact 720 tttttgcctctagctcctcccatagcattctcactgtggcccacactcacatgtacatggg 780 cactggcaggcacagaggtacctattgcatgcacaccaagcagcaagtgtgcacaccctgc 840 ccctactcgttccatgttagcggtccaagttccttccagatgtggatctgacaaggcacag 900 gaaAATAAAacaacaacaacaacaa 930

Figure 3. 3' RACE products. 3' RACE with the mouse-specific primer m0pn4 8 F generated two fragments of $857 \mathrm{bp}$ and $930 \mathrm{bp}$. The nucleotide sequence of each fragment is shown with the deduced amino acid sequence below. Exon boundaries are delineated with vertical blue lines, potential polyadenylation signals are underlined and potential protein kinase C sites are boxed. $A$, The 857 bp fragment consists of 425 bp of coding sequence ( 104 bp of exon 8 and 321 bp of exon 9) and 432 bp of $3^{\prime}$ UTR contiguous to exon 9 and corresponds to Opn4L. B, The $930 \mathrm{bp} \mathrm{fragment} \mathrm{is} \mathrm{composed} \mathrm{of} 260 \mathrm{bp}$ of coding sequence split across 3 exons (104 bp of exon 8,117 bp of exon 9 and 39 bp of exon 10). The remaining 670 bp of $3^{\prime}$ UTR is contiguous to the newly identified exon 10 . This product corresponds to 0 pn4S.

putative posttranslational modification sites was performed using the PREDICTPROTEIN program (http://www.predictprotein. org/submit.html) (Rost et al., 2004), which revealed the presence of three potential N-glycosylation sites (amino acid positions 30, 34, and 87), three casein kinase II sites (amino acid positions 140, 411, and 418), and one cAMP phosphorylation site (at position 183) in Opn4L and Opn4S. Both isoforms also have six potential protein kinase $\mathrm{C}$ phosphorylation sites (amino acid positions $36,182,264,381,385$, and 401), 

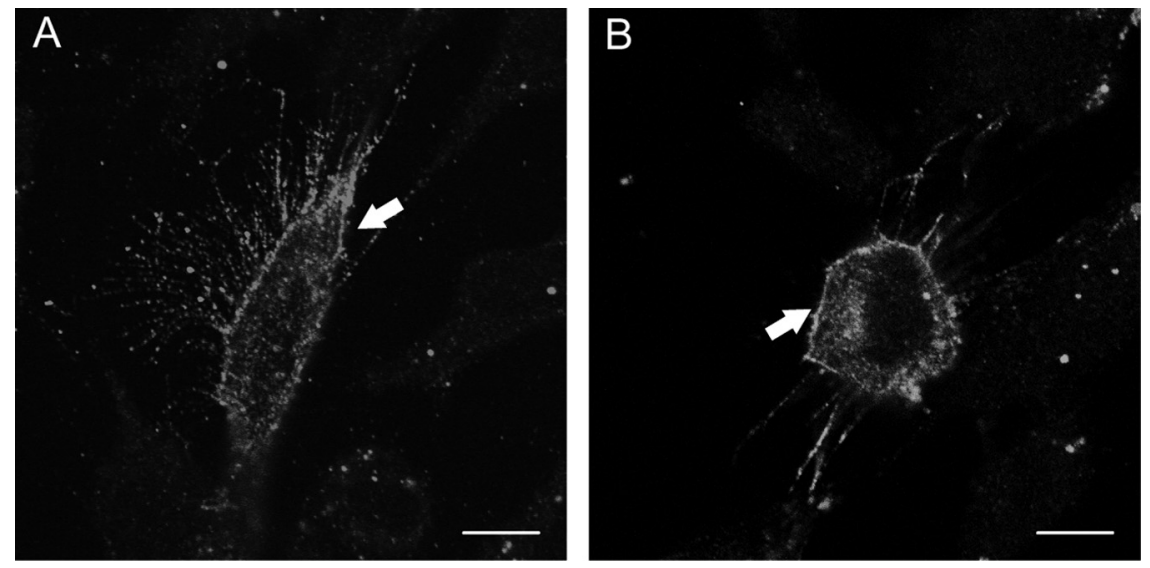

Figure 4. Opn4 localization in RGC-5 cells. RGC-5 cells were transfected with Opn4L $(\boldsymbol{A})$ and $0 \mathrm{pn} 4 \mathrm{~S}(\boldsymbol{B})$ and fixed after $24 \mathrm{~h}$ Melanopsin expression was detected using a rabbit anti-0pn4 antibody targeted to the $\mathrm{N}$ terminus of the protein (PA8331), and immunofluorescence signal was observed mainly on the plasma membrane (arrows). Scale bar, $10 \mu \mathrm{m}$.

A

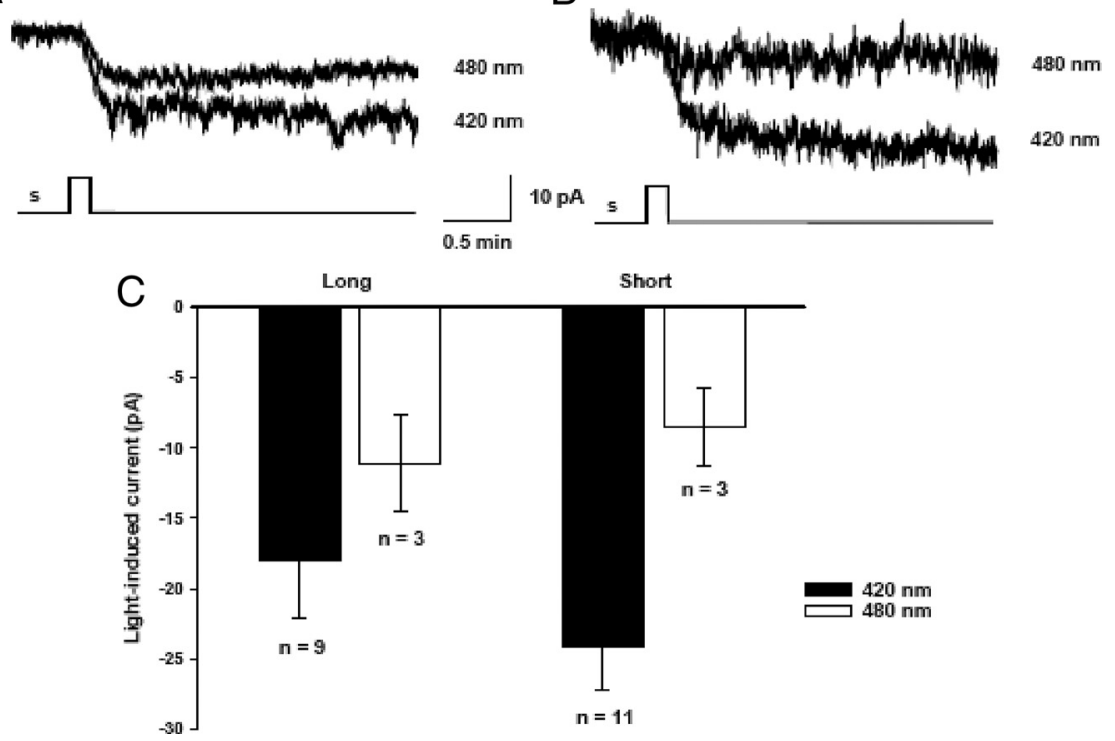

Figure 5. Heterologous expression of $0 \mathrm{pn} 4 \mathrm{~L}$ and $0 \mathrm{pn} 4 \mathrm{~S}$ suggests that both variants can form a sensory photopigment. Representative whole-cell patch-clamp recording from Neuro-2A cells transfected with Opn4L $(\boldsymbol{A})$ or Opn4S $(\boldsymbol{B})$, in the presence of 9-cis-retinal. Monochromatic light stimuli $420 \mathrm{~nm}$ and $480 \mathrm{~nm}$ (presented for $10 \mathrm{~s}$ at $8 \times 10^{14}$ photons $\cdot \mathrm{cm}^{-2} \cdot \mathrm{s}^{-1}$ ) evoke a stimulus-dependent inward current. Holding potential, $-50 \mathrm{mV}$. No differences in amplitude of responses, kinetics, or spectral sensitivity were observed between 0pn4L and 0pn4S.

but Opn4L has four more potential sites in its longer C-terminal tail (amino acid positions 460, 468, 481, and 517) (marked on Fig. 3A,B).

\section{Subcellular localization}

To test potential differences in processing between the Opn $4 \mathrm{~L}$ and Opn4S, both isoforms were expressed in the rat retinal ganglion cell line RGC-5. RGC-5 cells have been reported to have many of the properties of retinal ganglion cells (Krishnamoorthy et al., 2001) and should therefore process these isoforms similarly to retinal ganglion cells in vivo. RGC-5s did not express detectable levels of endogenous Opn4, but immunofluorescent labeling of transfected cells with an antibody raised against the $\mathrm{N}$ terminus region of melanopsin, present in both isoforms, revealed that both Opn4L and Opn $4 \mathrm{~S}$ were trafficked predominantly to the plasma membrane in $\sim 90 \%$ of cells ana- lyzed (Fig. 4). No staining of nontransfected cells was observed with PAS8331, secondary antibody only controls were also negative. No differences were observed in the processing of these isoforms in RGC- 5 cells, or the mouse neuronal cell line, Neuro-2A (supplemental Fig. 3, available at www.jneurosci.org as supplemental material).

\section{Opn4L and Opn4S both encode a} functional sensory photopigment

To directly determine whether both isoforms encode a functional sensory pigment, we used the Neuro-2A heterologous expression system previously used to examine melanopsin (Melyan et al., 2005; Bellingham et al., 2006). Neuro-2A cells were transiently transfected with either Opn4L or Opn4S in the expression vector pIRES2-AcGFP which also contains a GFP reporter gene. Whole-cell patchclamp recordings from fluorescent cells revealed light-dependent inward currents in cells transfected with either Opn $4 L$ or $O p n 4 S$, in the presence but not the absence of 9-cis-retinal or 11-cis-retinal chromophore (Fig. 5). Increasing the duration of light stimuli elicited inward currents of increasing amplitude (supplemental Fig. 2, available at www. jneurosci.org as supplemental material). For both $O p n 4 L$ - and Opn4S-transfected cells, the light-evoked responses show only limited recovery over periods of 10-30 min following stimulation. Responses were absent from cells transfected with GFP alone (data not shown).

In all aspects, the light-evoked currents observed in the cells transfected with either Opn4L or Opn4S are consistent with those obtained with human melanopsin in this expression system (Melyan et al., 2005) and suggest that both isoforms can form a functional retinaldehyde-dependent sensory photopigment. In the Neuro-2A heterologous expression system, we could find no significant differences in the lightevoked responses of either isoform with regards to response amplitude, kinetics, or spectral sensitivity.

\section{Opn4L and Opn4S are differentially expressed in the mammalian retina}

Isoform-specific antibodies were raised against peptides corresponding to the differing C-terminal regions of Opn4L and Opn4S (shown in Fig. 1). The specificity of these antibodies was confirmed by immunolabeling of Neuro-2A cells transiently transfected with Opn4L or Opn4S. Both antibodies were found to be isoform specific, with the anti-Opn $4 \mathrm{~L}$ antibody only labeling $O p n 4 L$-transfected cells, and the anti-Opn 4 S antibody only labeling Opn4S-transfected cells. In each case labeling was only observed for GFP-positive cells with no labeling observed in 


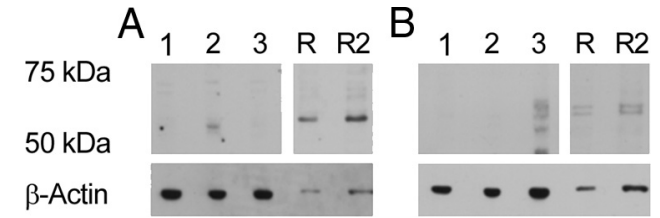

Figure 6. Western blot analysis of isoform-specific expression of melanopsin in retina. A, Western blot analysis using 0pn4S antibody. Lane 1, Wild-type Neuro-2A cells; lane 2, Opn4S-transfected cells; lane 3, 0pn4L-transfected cells. R, Tau-lac $Z^{+/-}$retina single load; R2, Tau-lac ${ }^{+/-}$retina double load. $\boldsymbol{B}$, Western blot analysis using $0 \mathrm{pn} 4 \mathrm{~L}$ antibody, gel loading as previous figure. $\beta$-Actin was used to confirm equal loading of the gel.

neighboring untransfected cells (supplemental Fig. 3, available at www.jneurosci.org as supplemental material) or nontransfected controls (data not shown). The antibodies showed equal levels of staining in cells expressing similar levels of the GFP transfection reporter. As expected the N-terminal melanopsin antibodylabeled cells transfected with both Opn4L and Opn4S (supplemental Fig. 3, available at www.jneurosci.org as supplemental material).

Western blotting of transiently transfected cells and adult retinal tissue was undertaken with the isoform-specific antibodies. Immunoreactive proteins were detected at $\sim 55$ and $60 \mathrm{kDa}$ by the short and long isoform-specific antibodies respectively (Fig. $6 A, B)$. These masses are comparable to the calculated molecular weights of $51 \mathrm{kDa}$ for Opn4S and $57 \mathrm{kDa}$ for Opn4L. The additional immunoreactive proteins observed with the Opn4L antibody, in both transiently transfected cells and retinal samples, could result from differential posttranslational modification of the protein such as glycosylation or phosphorylation, which is currently under investigation. An alternative explanation is that the expression of Opn4L at high concentrations in mammalian cells results in differential processing of the protein, as suggested with melanopsin from other species (Terakita et al., 2008). Western blot analysis confirmed a higher concentration of Opn4S than Opn4L when compared with $\beta$-actin loading controls (Fig. $6 A, B)$. The higher expression of Opn $4 \mathrm{~S}$ correlates with the quantitative PCR analysis which demonstrated that the Opn4S transcript is 40 times more abundant in the mouse retina than the Opn4L transcript.

Initially, immunolabeling of wild-type mouse eye sections was performed using either the anti-Opn4L or the anti-Opn4S antibody alone (single labeling). These experiments confirmed the expression of both long and short isoforms of melanopsin in a subset of RGCs within the mouse retina (Fig. 7). The majority of Opn4L-positive cells had relatively low levels of staining and cellular processes were often difficult to visualize. In contrast, Opn4S-positive cells appeared brightly labeled and cellular processes were more easily observed. When visible, the processes of Opn4L-positive cells revealed a number of subpopulations. Opn4L-positive cells were observed with processes in the outer IPL close to the INL or were found to be bistratified with processes located both in the inner $(\mathrm{ON})$ and outer (OFF) layers of the IPL (Fig. $7 A, B$ ). A second population of Opn4L-positive cells were identified whose processes were confined to the inner layer of the IPL (Fig. 7C,D). Opn4S-positive cells had processes localized to the outer IPL or were bistratified with processes in both the inner and outer layers of the IPL (Fig. 7E-H). Cells with processes confined only to the inner layer of the IPL were absent in Opn4S single-labeling experiments.

Subsequent double labeling using both anti-Opn4L and antiOpn4S confirmed a differential pattern of expression for each isoform. The majority of melanopsin-positive RGC cells ( 70\%) were found to express both the long and short isoforms of melanopsin, with processes clearly evident in the outer IPL (Fig. $8 \mathrm{~A}$ ). In these cells the intensity of Opn 4 S labeling was markedly higher than that of Opn4L. A smaller population of pRGCs $(\sim 30 \%)$ were found to express only the Opn4L isoform, and when visible, had processes confined to the inner layer of the IPL (Fig. $8 \mathrm{~A}$ ). Colabeling experiments using an N-terminal antibody, which recognizes both isoforms, and the anti-Opn4S antibody again showed a high degree of colocalization, with $\sim 70 \%$ of all cells labeled with the N-terminal melanopsin antibody also labeling with Opn4S (data not shown).

Further double-labeling experiments were then performed on eye sections from tau-lacZ ${ }^{+/-}$mice (Hattar et al., 2002), using each isoform-specific antibody with a chicken anti- $\beta$-galactosidase antibody. When both anti-Opn $4 \mathrm{~S}$ and anti- $\beta$-gal antibodies were used together all the immunopositive cells were colabeled (Fig. $8 \mathrm{~B}$ ). Whereas staining with anti-Opn $4 \mathrm{~L}$ and anti- $\beta$-gal revealed subpopulations of cells, one expressing both Opn4L and $\beta$-gal, and a second subset of Opn4L-positive cells lacking $\beta$-gal expression (Fig. 8C). For all antibodies, controls including omission of primary antibody, and absorption of antibody with immunizing peptides were negative.

\section{Discussion}

The isolation of both human and mouse melanopsin was originally described in 2000 (Provencio et al., 2002) and highlighted that the predicted C-terminal tail of the mouse protein was 46 aa longer than that of the predicted human protein. This was not thought to be relevant as humans and mice diverged $\sim 65,000,000$ years ago. However, the subsequent isolation of the rat Opn4 gene (Hattar et al., 2002) revealed the unexpected finding that the predicted C-terminal tail of the rat protein was more similar to that of human than mouse (Fig. $1 \mathrm{~A}$ ). The additional observation that the human melanopsin gene consists of 10 exons and the mouse only of 9 (Provencio et al., 2000) and the demonstration in a recent study that the Opn4 gene in the Australian marsupial, the fat-tailed dunnart, also consisted of 10 exons (Pires et al., 2007) prompted us to undertake a comprehensive examination of the mouse gene. This analysis revealed that the mouse Opn4 gene also consists of 10 exons spanning 9 $\mathrm{kb}$ of genomic DNA and that transcription at this locus generates two isoforms, Opn4L and Opn4S, by alternate splicing (Fig. 2). Both Opn4 isoforms are expressed in adult mouse retina and are restricted to a subset of retinal ganglion cells. However, quantitative PCR shows that the short isoform, Opn4S, is expressed at levels $40 \times$ greater than the long isoform, Opn $4 L$ (supplemental Fig. 1, available at www.jneurosci.org as supplemental material). Whether this result is due to higher de novo expression or greater mRNA stability remains to be determined.

Melanopsin belongs to the opsin superfamily of G-protein coupled receptors (GPCRs), which function through the activation of a guanine nucleotide binding protein (G-protein) and an effector enzyme. Opsins consist of seven $\alpha$-helical transmembrane regions which form a bundle within the membrane creating a hollow cavity on the extracellular side that serves as a binding site for the chromophore, retinal (Palczewski et al., 2000). The predicted proteins encoded by Opn4L (521 aa) and Opn4S (466 aa) are identical for the first 454 aa, only differing in the length of their C-terminal tails. Both isoforms encode a seven transmembrane domain protein and contain all of the key features expected to be present in an opsin (see Fig. 1). However, to test whether the newly described Opn4S is also functional, the 

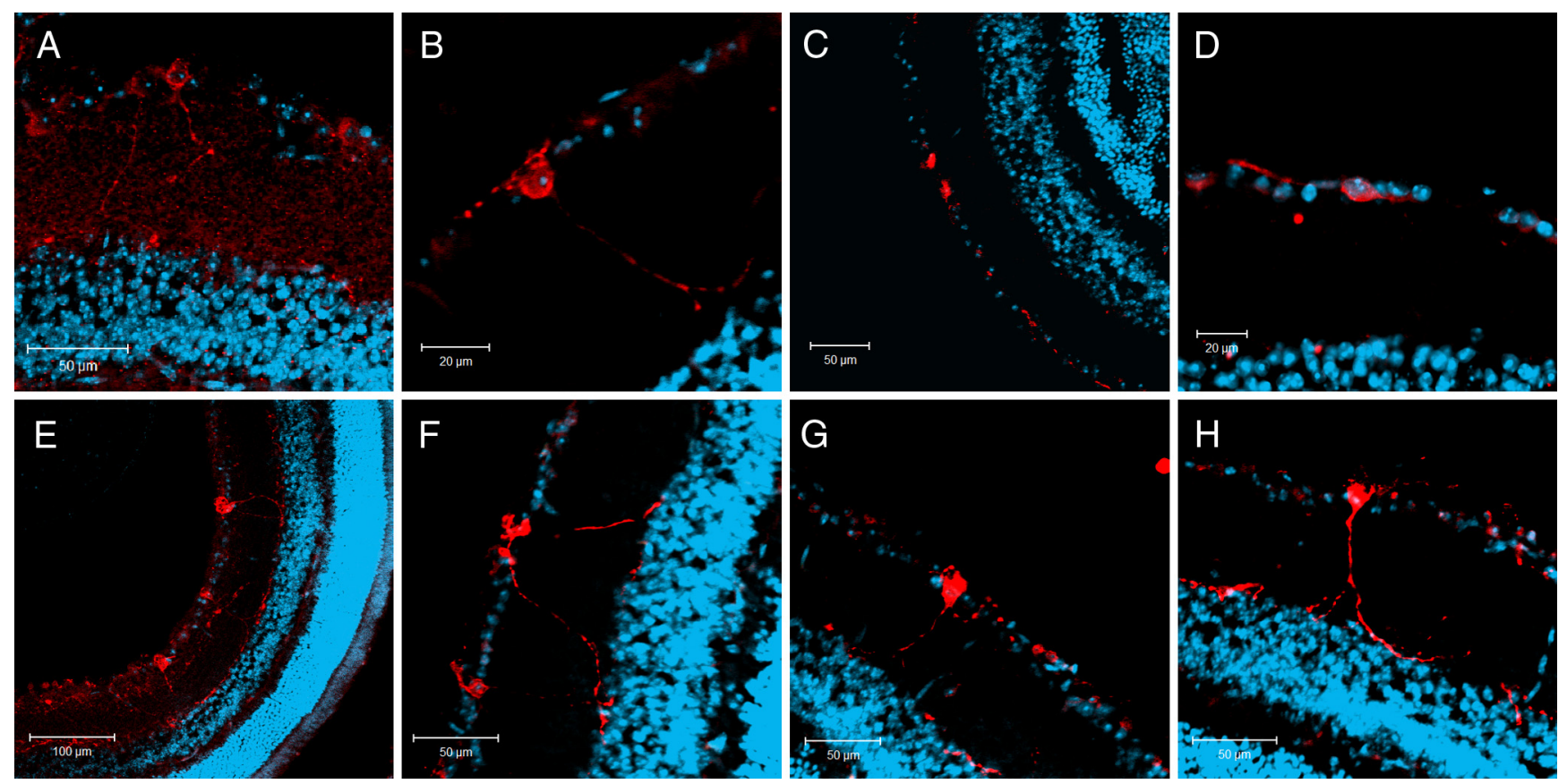

Figure 7. Single immunolabeling of the mouse retina with anti-0pn4L and anti-0pn4S antibodies. Single labeling of whole eye sections with anti-0pn4L $(\boldsymbol{A}-\boldsymbol{D})$ and anti-0pn4S $(\boldsymbol{E}-\boldsymbol{H})$ antibodies (red) and DAPI counterstain (blue) shows that both isoforms are expressed in a subset of RGCs. Higher levels of labeling were observed for 0pn4S compared with Opn4L. When visible, the majority of $0 \mathrm{pn} 4 \mathrm{~L}$ cells have dendrites localized near the inner nuclear layer (INL) or are bistratified with processes in the INL and ganglion cell layer. A number of Opn4L cells were also identified whose processes were confined to the vicinity of the ganglion cell layer. All 0pn4S-positive cells have dendrites located in the INL and are often bistratified with processes also seen in the ganglion cell layer.

full-length coding sequences of both isoforms were cloned into a mammalian expression vector. Transient transfection of Opn4L and Opn4S into the rat retinal ganglion cell line, RGC-5, and the mouse neuronal cell line, Neuro-2A, showed that both were trafficked predominantly to the plasma membrane and that there was no difference in the processing of these isoforms (Fig. 4; supplemental Fig. 3, available at www.jneurosci.org as supplemental material). Similarly, no functional differences were observed for Opn4L and Opn4S following expression in the Neuro-2A expression system used previously to examine both human and chicken melanopsin (Melyan et al., 2005; Bellingham et al., 2006). Both Opn4L- and Opn4S-transfected cells demonstrated light-dependent inward currents only in the presence of retinaldehyde chromophore. There were no differences in amplitude, kinetics or spectral sensitivity of responses recorded from the two forms. However in this heterologous expression system the opsin is acting through a non-native G-protein signaling cascade. We therefore cannot assume that the light response in native pRGCs will necessarily be equivalent for Opn4L and Opn4S. Indeed differences in the C-terminal motifs in the two isoforms may result in coupling to quite discrete transduction cascades within the native cell environment. Until recently GPCRs were thought to be a homogeneous family with the majority $(>90 \%)$ being intronless. However, it is now clear that a small subset undergo alternate splicing mostly at the $\mathrm{C}$ terminus. Little is known about the functional roles of these splice variants but differences relating to ligand binding, signaling efficiency, constitutive activity and desensitization have been reported (for review, see Minneman, 2001)

It was previously assumed that the vertebrates had a single melanopsin gene, but Bellingham et al. (2006) described the identification of two distinct melanopsin genes in chicken, Opn4m and Opn4x. They also demonstrated that the Opn4x gene has been lost from the mammalian lineage. The alternate splicing described in this study may therefore generate functional diversity required in the mammals. However, there is now evidence that C-terminal splice variants are expressed from both chicken genes (Torii et al., 2007), so this may be another example of the reduction in photosensory capability seen in the mammals.

Immunolabeling of mouse eye sections with isoform-specific antibodies demonstrates that both Opn4L and Opn4S are expressed within the mouse retina. Double immunolabeling using Opn4L and Opn4S antibodies together revealed distinct subpopulations of melanopsin-expressing cells. These observations are consistent with previous reports that have described subclasses of melanopsin ganglion cells that can be characterized based on the nature of their dendrites, termed M1 (type I), M2 (type II), or bistratified (type III) (Hattar et al., 2006; Viney et al., 2007; Schmidt et al., 2008). The majority of melanopsin-positive cells $(\sim 70 \%)$ were labeled with both Opn4S and Opn4L antibodies, with higher levels of Opn4S labeling observed compared with Opn4L. These cells stratified in the OFF layer of the IPL near the border of the INL (M1 or type I) or were bistratified with processes evident in both the OFF layer and ON layer of the IPL (type III). The remaining cells $(\sim 30 \%)$ were labeled weakly for Opn4L only and their processes stratified in the ON layer of the IPL near to the GCL and resemble those previously described as M2 (type II).

A number of previous studies using heterozygous taulac $\mathrm{Z}^{+/-}$mice have distinguished M1- and M2-type cells based on morphology and differential staining with $\mathrm{N}$-terminal melanopsin and $\beta$-gal antibodies (Provencio et al., 2002; Hattar et al., 2006; Baver et al., 2008). M1-type cells stain with both the $\mathrm{N}$-terminal melanopsin and $\beta$-gal antibody, whereas M2-type cells only stain with the melanopsin antibody. This unexpected finding has been attributed to a low level of expression of the $\beta$-galactosidase gene that is undetectable in M2 cells. In this study double labeling of tau-lacZ $\mathrm{Z}^{+/-}$mice with anti-Opn4S or anti- 


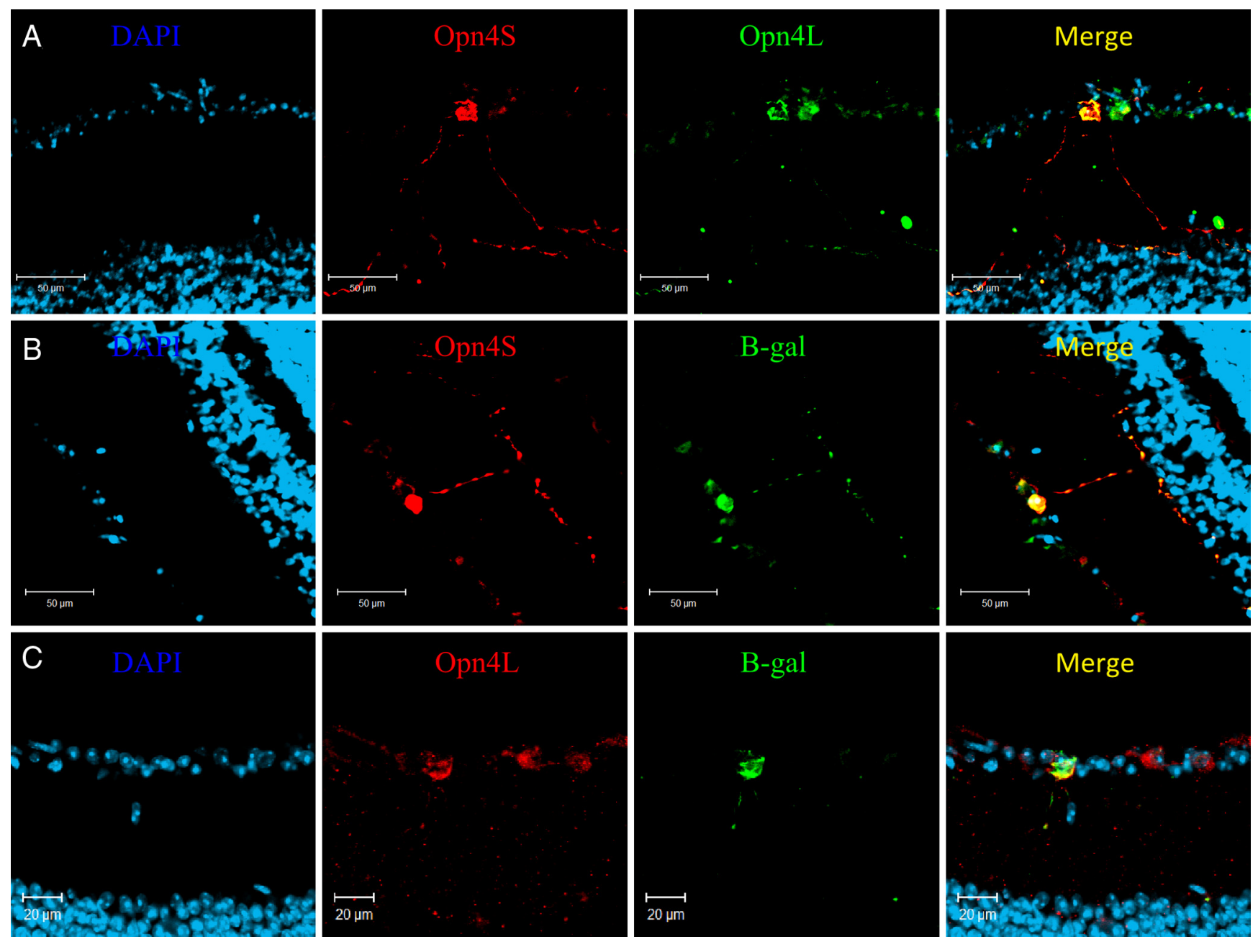

Figure 8. Immunolabeling of the mouse retina shows a differential pattern of expression for Opn4L and 0pn4S. $A$, Double labeling with 0pn4L (green) and 0pn4S (red) identified two subsets of pRGCS, those expressing both 0pn4L and 0pn4S and a second subset of cells expressing only 0pn4L. B, Double labeling with $\beta$-gal (green) and Opn4S (red) shows a 100\% overlap of expression, with all cells positive for both $\beta$-gal and 0pn4S. C, Labeling with $\beta$-gal (green) and 0pn4L (red) reveals a subset of 0pn4L-positive cells that lack detectable $\beta$-gal expression. For all images, DAPl is blue.

Opn4L and a $\beta$-gal antibody revealed a $100 \%$ overlap in expression of Opn 4 S and $\beta$-gal, with $\beta$-gal expression absent from a subset of Opn4L-positive cells. Based on the morphology of their processes and the coexpression of $\beta$-gal, the Opn4S-positive pRGCs identified in our study would again seem to correspond to those previously described as M1 (type I) or bistratified (type III). Morphological characterization of the "Opn4L-only" cells identified in our studies is more difficult due to the low levels of staining typically observed for these cells. However, in examples where processes are clearly visible for Opn4L-only cells, they stratify in the ON layer of the IPL and resemble those of M2 (type II) cells. This conclusion is supported by the observation that M2-type cells are only detected using the Opn4L antibody, and are absent from single-labeling experiments using the Opn4S antibody. The characteristically low levels of melanopsin staining and the lack of detectable $\beta$-gal in these cells further indicate that they are M2 cells.

Our results strongly suggest that expression of Opn $4 \mathrm{~S}$ is restricted to $\beta$-gal-positive cells and is absent from M2-type cells. These findings are corroborated in a recent study by Baver et al. (2008), who reported that an antibody raised against the $\mathrm{C}$ terminus of the rat Opn4 sequence selectively labels the $\beta$-galpositive subset of pRGCs in tau-lac $\mathrm{Z}^{+/-}$mice. The epitope recognized by this antibody is not present in the previously re- ported mouse Opn4 sequence (termed Opn4L here) (Provencio et al., 2000) but is present in the novel Opn 4 S sequence described here. Hence the data presented by Baver et al. (2008) confirms that Opn4S expression is absent in M2-type cells. Based on morphology and coexpression of the $\beta$-gal reporter, our studies suggest that $70 \%$ of pRGCs are Opn4S-positive cells (M1 and bistratified), with the remaining 30\% being M2-type cells. These results are in contrast with previous studies, which have suggested that between 40 and 50\% of pRGCs are M2 (Viney et al., 2007; Baver et al., 2008; Schmidt et al., 2008). A possible explanation for this disparity is that due to the relatively low expression of Opn4L observed in the Opn4S-negative cells, we may have failed to detect a number of these cells. Alternative explanations could include age-related differences in the mice used for our studies and circadian variation in expression (GonzálezMenéndez et al., 2009).

pRGCs are known to receive light information from rods and/or cones (Altimus et al., 2008; Güler et al., 2008) via synaptic contacts with bipolar and amacrine cells (Belenky et al., 2003; Viney et al., 2007; Wong et al., 2007). Processes of pRGCs located in the OFF layer of the IPL are known to receive input from OFF bipolar cells and are also closely associated with dopaminergic amacrine cells (Belenky et al., 2003; Østergaard et al., 2007; Viney et al., 2007; Vugler et al., 2007; Wong et al., 2007; Zhang et al., 
2008), whereas cells with processes in the ON layer of the IPL receive inputs from ON bipolar cells (Wong et al., 2007). This difference in retinal architecture offers a clear mechanism to differentially regulate the functions of distinct pRGC subtypes. However it has also been reported that M1-type cells (that have processes in the OFF layer of the IPL) may receive direct (Wong et al., 2007; Hoshi et al., 2009) or indirect (Pickard et al., 2009) excitatory inputs from the ON bipolar cells, although the mechanisms involved are not entirely clear.

The precise natures of the synaptic contacts influencing the cells identified in this study have not been fully characterized. We have confirmed that both Opn4L- and Opn4S-positive processes in the OFF layer of the IPL interact closely with processes of dopaminergic amacrine cells (data not shown) but have not fully characterized the nature of bipolar cell contacts to either the Opn4S (and Opn4L)-positive M1-type cells or the Opn4L-only M2-type cells. However, our data identify an intriguing possibility that may have functional relevance. As pRGCs with processes in the OFF layer of the IPL (M1) express predominantly Opn4S (in addition to lower levels of Opn4L), and pRGCs that receive exclusively ON inputs (M2 cells) express only Opn4L, it would seem that the dominant isoform of melanopsin in cells influenced by the OFF pathway is Opn4S, whereas the dominant isoform in cells receiving exclusively $\mathrm{ON}$ inputs is $\mathrm{Opn} 4 \mathrm{~L}$.

In addition to differences in cellular morphology and stratification of dendrites, a number of previous studies have identified subsets of pRGCs based on functional differences. At least three different type of response have been observed during $\mathrm{Ca}^{2+}$ imaging (Sekaran et al., 2003) and MEA recordings of mouse retina explants (Tu et al., 2005). These studies did not correlate these different responses with the morphologically distinct subsets of pRGCs. However, more recently, Schmidt and Kofuji (2009) have reported functional differences in light responses recorded from M1- and M2-type pRGCs using dual whole-cell electrophysiology. M1 cells were shown to be significantly more sensitive to light than M2 cells. In addition, the responses of M1 cells were significantly larger and consisted of a rapid time inactivating component and smaller sustained component. In contrast, M2 cells exhibited markedly smaller responses which showed little signs of time dependant inactivation. This study suggests that the difference in light sensitivity between M1 and M2 cells may be influenced by levels of melanopsin expression, differences in resting membrane potential, input resistance and ion channel expression. Our data now offer a potential molecular explanation for the functional differences observed between subpopulations of pRGCs based on the differential expression of Opn4L and Opn4S within these cells. The different C-terminal regions may potentially facilitate differential interactions with intracellular signaling molecules, and in turn convey functional differences to Opn4L and Opn4S-expressing cells.

This study details the identification of two distinct isoforms of melanopsin in the mouse retina, a previously described long isoform and a new novel short isoform which more closely resembles the sequences of rat and human melanopsin. Both isoforms are capable of forming functional pigments in vitro and show a differential pattern of expression in subpopulations of pRGCs. Our results strongly indicate that Opn $4 \mathrm{~S}$ is the most abundant isoform in the mouse retina, although Opn $4 \mathrm{~L}$ is actually expressed in all pRGCs with expression of Opn 4 S restricted to M1 (type I) and bistratified (type III) cells. These findings provide further insight into the complexity of melanopsin signaling pathways and offer a potential mechanism to explain the functional diversity observed between different subsets of pRGCs. The ap- plication of RNAi-based techniques is now needed to investigate the specific contributions of Opn $4 \mathrm{~L}$ and Opn $4 \mathrm{~S}$ isoforms to the different functional responses observed from individual pRGCs, but also to evaluate the contribution of each isoform to more complex behavioral responses such as pupillary light responses and circadian entrainment.

\section{References}

Altimus CM, Güler AD, Villa KL, McNeill DS, Legates TA, Hattar S (2008) Rods-cones and melanopsin detect light and dark to modulate sleep independent of image formation. Proc Natl Acad Sci U S A 105:1999820003.

Baver SB, Pickard GE, Sollars PJ, Pickard GE (2008) Two types of melanopsin retinal ganglion cell differentially innervate the hypothalamic suprachiasmatic nucleus and the olivary pretectal nucleus. Eur J Neurosci 27:1763-1770.

Belenky MA, Smeraski CA, Provencio I, Sollars PJ, Pickard GE (2003) Melanopsin retinal ganglion cells receive bipolar and amacrine cell synapses. J Comp Neurol 460:380-393.

Bellingham J, Chaurasia SS, Melyan Z, Liu C, Cameron MA, Tarttelin EE Iuvone PM, Hankins MW, Tosini G, Lucas RJ (2006) Evolution of melanopsin photoreceptors: discovery and characterization of a new melanopsin in nonmammalian vertebrates. PLoS Biol 4:e254.

Berson DM, Dunn FA, Takao M (2002) Phototransduction by retinal ganglion cells that set the circadian clock. Science 295:1070-1073.

Dacey DM, Liao HW, Peterson BB, Robinson FR, Smith VC, Pokorny J, Yau KW, Gamlin PD (2005) Melanopsin-expressing ganglion cells in primate retina signal colour and irradiance and project to the LGN. Nature 433:749-754

González-Menéndez I, Contreras F, Cernuda-Cernuda R, García-Fernández JM (2009) Daily rhythm of melanopsin-expressing cells in the mouse retina. Front Cell Neurosci 3:3.

Güler AD, Ecker JL, Lall GS, Haq S, Altimus CM, Liao HW, Barnard AR, Cahill H, Badea TC, Zhao H, Hankins MW, Berson DM, Lucas RJ, Yau KW, Hattar S (2008) Melanopsin cells are the principal conduits for rod-cone input to non-image-forming vision. Nature 453:102-105.

Hankins MW, Peirson SN, Foster RG (2008) Melanopsin: an exciting photopigment. Trends Neurosci 31:27-36.

Hattar S, Liao HW, Takao M, Berson DM, Yau KW (2002) Melanopsincontaining retinal ganglion cells: architecture, projections, and intrinsic photosensitivity. Science 295:1065-1070.

Hattar S, Lucas RJ, Mrosovsky N, Thompson S, Douglas RH, Hankins MW, Lem J, Biel M, Hofmann F, Foster RG, Yau KW (2003) Melanopsin and rod-cone photoreceptive systems account for all major accessory visual functions in mice. Nature 424:76-81.

Hattar S, Kumar M, Park A, Tong P, Tung J, Yau KW, Berson DM (2006) Central projections of melanopsin-expressing retinal ganglion cells in the mouse. J Comp Neurol 497:326-349.

Hoshi H, Liu WL, Massey SC, Mills SL (2009) ON inputs to the OFF layer: bipolar cells that break the stratification rules of the retina. J Neurosci 29:8875-8883

Kosmaoglou M, Cheetham ME (2008) Calnexin is not essential for mammalian rod opsin biogenesis. Mol Vis 14:2466-2474.

Krishnamoorthy RR, Agarwal P, Prasanna G, Vopat K, Lambert W, Sheedlo HJ, Pang IH, Shade D, Wordinger RJ, Yorio T, Clark AF, Agarwal N (2001) Characterization of a transformed rat retinal ganglion cell line. Brain Res Mol Brain Res 86:1-12.

Lucas RJ, Hattar S, Takao M, Berson DM, Foster RG, Yau KW (2003) Diminished pupillary light reflex at high irradiances in melanopsinknockout mice. Science 299:245-247.

Melyan Z, Tarttelin EE, Bellingham J, Lucas RJ, Hankins MW (2005) Addition of human melanopsin renders mammalian cells photoresponsive. Nature 433:741-745.

Minneman KP (2001) Splice variants of G protein-coupled receptors. Mol Interv 1:108-116.

Østergaard J, Hannibal J, Fahrenkrug J (2007) Synaptic contact between melanopsin-containing retinal ganglion cells and rod bipolar cells. Invest Ophthalmol Vis Sci 48:3812-3820.

Palczewski K, Kumasaka T, Hori T, Behnke CA, Motoshima H, Fox BA, Le Trong I, Teller DC, Okada T, Stenkamp RE, Yamamoto M, Miyano M (2000) Crystal structure of rhodopsin: a G protein-coupled receptor. Science 289:739-745. 
Panda S, Sato TK, Castrucci AM, Rollag MD, DeGrip WJ, Hogenesch JB, Provencio I, Kay SA (2002) Melanopsin (Opn4) requirement for normal light-induced circadian phase shifting. Science 298:2213-2216.

Panda S, Nayak SK, Campo B, Walker JR, Hogenesch JB, Jegla T (2005) Illumination of the melanopsin signaling pathway. Science 307:600-604.

Peirson SN, Butler JN, Foster RG (2003) Experimental validation of novel and conventional approaches to quantitative real-time PCR data analysis. Nucleic Acids Res 31:e73.

Peirson SN, Bovee-Geurts PH, Lupi D, Jeffery G, DeGrip WJ, Foster RG (2004) Expression of the candidate circadian photopigment melanopsin (Opn4) in the mouse retinal pigment epithelium. Brain Res Mol Brain Res 123:132-135.

Pickard GE, Baver SB, Ogilvie MD, Sollars PJ (2009) Light-induced fos expression in intrinsically photosensitive retinal ganglion cells in melanopsin knockout (opn4) mice. PLoS One 4:e4984.

Pires SS, Shand J, Bellingham J, Arrese C, Turton M, Peirson S, Foster RG, Halford S (2007) Isolation and characterization of melanopsin (Opn4) from the Australian marsupial Sminthopsis crassicaudata (fat-tailed dunnart). Proc Biol Sci 274:2791-2799.

Provencio I, Jiang G, De Grip WJ, Hayes WP, Rollag MD (1998) Melanopsin: An opsin in melanophores, brain, and eye. Proc Natl Acad Sci U S A 95:340-345.

Provencio I, Rodriguez IR, Jiang G, Hayes WP, Moreira EF, Rollag MD (2000) A novel human opsin in the inner retina. J Neurosci 20:600-605.

Provencio I, Rollag MD, Castrucci AM (2002) Photoreceptive net in the mammalian retina. This mesh of cells may explain how some blind mice can still tell day from night. Nature 415:493.

Qiu X, Kumbalasiri T, Carlson SM, Wong KY, Krishna V, Provencio I, Berson DM (2005) Induction of photosensitivity by heterologous expression of melanopsin. Nature 433:745-749.

Rost B, Yachdav G, Liu J (2004) The PredictProtein server. Nucleic Acids Res 32:W321-W326.

Ruby NF, Brennan TJ, Xie X, Cao V, Franken P, Heller HC, O’Hara BF (2002) Role of melanopsin in circadian responses to light. Science 298:2211-2213.

Saliba RS, Munro PM, Luthert PJ, Cheetham ME (2002) The cellular fate of mutant rhodopsin: quality control, degradation and aggresome formation. J Cell Sci 115:2907-2918.

Schmidt TM, Kofuji P (2009) Functional and morphological differences among intrinsically photosensitive retinal ganglion cells. J Neurosci 29:476-482.

Schmidt TM, Taniguchi K, Kofuji P (2008) Intrinsic and extrinsic light responses in melanopsin-expressing ganglion cells during mouse development. J Neurophysiol 100:371-384.

Sekaran S, Foster RG, Lucas RJ, Hankins MW (2003) Calcium imaging reveals a network of intrinsically light-sensitive inner-retinal neurons. Curr Biol 13:1290-1298.

Sekaran S, Lall GS, Ralphs KL, Wolstenholme AJ, Lucas RJ, Foster RG, Hankins MW (2007) 2-Aminoethoxydiphenylborane is an acute inhibitor of directly photosensitive retinal ganglion cell activity in vitro and in vivo. J Neurosci 27:3981-3986.

Terakita A, Tsukamoto H, Koyanagi M, Sugahara M, Yamashita T, Shichida Y (2008) Expression and comparative characterization of Gq-coupled invertebrate visual pigments and melanopsin. J Neurochem 105:883-890.

Torii M, Kojima D, Okano T, Nakamura A, Terakita A, Shichida Y, Wada A, Fukada Y (2007) Two isoforms of chicken melanopsins show blue light sensitivity. FEBS Lett 581:5327-5331.

Tu DC, Zhang D, Demas J, Slutsky EB, Provencio I, Holy TE, Van Gelder RN (2005) Physiologic diversity and development of intrinsically photosensitive retinal ganglion cells. Neuron 48:987-999.

Viney TJ, Balint K, Hillier D, Siegert S, Boldogkoi Z, Enquist LW, Meister M, Cepko CL, Roska B (2007) Local retinal circuits of melanopsincontaining ganglion cells identified by transsynaptic viral tracing. Curr Biol 17:981-988.

Vugler AA, Redgrave P, Semo M, Lawrence J, Greenwood J, Coffey PJ (2007) Dopamine neurones form a discrete plexus with melanopsin cells in normal and degenerating retina. Exp Neurol 205:26-35.

Wong KY, Dunn FA, Graham DM, Berson DM (2007) Synaptic influences on rat ganglion-cell photoreceptors. J Physiol 582:279-296.

Zhang DQ, Wong KY, Sollars PJ, Berson DM, Pickard GE, McMahon DG (2008) Intraretinal signaling by ganglion cell photoreceptors to dopaminergic amacrine neurons. Proc Natl Acad Sci U S A 105:14181-14186. 